\title{
MULTICULTURALISMO E MOVIMENTOS SOCIAIS: O PRIVADO PREOCUPADO COM O PÚBLICO
}

\section{José Carlos Moreira da Silva Filho}

Doutor em Direito das Relações Sociais pela Universidade Federal do Paraná (UFPR), Mestre em Teoria e Filosofia do Direito pela Universidade Federal de Santa Catarina (UFSC), Bacharel em Direito pela Universidade de Brasília (UnB) - Professor do Programa de Pós-graduação em Direito (Mestrado), da Especialização em Direito Privado e da Graduação em Direito da Universidade do Vale do Rio dos Sinos (UNISINOS) e-mail: josecarlosfilho@terra.com.br

RESUMO: O artigo situa os movimentos sociais e a discussão do multiculturalismo no cenário contemporâneo de indefinição das esferas pública e privada, levando em conta as peculiaridades do tema na América Latina e em países ocidentais de capitalismo desenvolvido. Identifica-se uma permanente tensão entre a tendência de desintegração da esfera pública e o desenvolvimento de uma política de reconhecimento das diferenças, a partir da qual se possa fazer frente ao risco da anomia comunitária.

PALAVRAS-CHAVE: público e privado; movimentos sociais; multiculturalismo; direitos sociais; igualdade; identidade e reconhecimento. 
Nos dias que se seguem, a célebre distinção de Benjamin Constant entre a liberdade dos antigos e a liberdade dos modernos parece assumir uma intensidade nunca antes percebida. O arguto pensador liberal francês concluía, à época imediatamente posterior à revolução francesa, que, na democracia moderna, não restava tempo ou interesse para que as pessoas se envolvessem com os assuntos da esfera pública, preponderando os seus respectivos interesses privados. Robespierre, dizia Constant, queria o impossível: impor aos modernos o envolvimento ativo com as questões políticas.

A análise de Benjamin Constant, porém, conferia a essa ausência do plano público uma conotação positiva. A liberdade que interessa ao homem moderno é a liberdade para "preencher seus dias e sua horas de maneira mais condizente com suas inclinações, com suas fantasias". " Esta linha de raciocínio estimulou o desenvolvimento de uma democracia representativa, onde o "peso" de administrar e de se preocupar com o que é público transfere-se ao governo e aos políticos, restando à participação dos cidadãos o exercício do voto periódico. Delimita-se, assim, a versão moderna das dimensões pública e privada: de um lado o Estado, de outro a sociedade civil.

Hoje vive-se um cenário no qual a dimensão pública, tradicional campo do Estado, perde boa parte do significado que possuía, especialmente enquanto espaço de emancipação social e política. Paira uma grande descrença sobre a possibilidade de um governo, de esquerda, de centro ou de direita, ser o responsável direto por transformações rumo à concretização de uma sociedade melhor. No vácuo deste sentido ausente, todavia, não se chega a constituir claramente um outro espaço para o público. Eis porque nem sequer o voto nos representantes políticos parece mobilizar os membros da sociedade em prol de causas comuns. O otimismo de Constant sobre a liberdade dos modernos transforma-se, assim, no temor do abandono completo destas causas.

O tema do multiculturalismo, especialmente quando articulado com a demanda dos direitos coletivos (tradicionalmente compreendidos enquanto direitos sociais), pode trazer importantes esclarecimentos quando desenvolvido a partir

\footnotetext{
${ }^{1}$ CONSTANT, Benjamin. "Da liberdade dos antigos comparada à dos modernos." In: Filosofia política, Porto Alegre, L\&PM, 1985, p.10.
} 
desse pano de fundo do público e do privado. Antes de avançar nesta direção, porém, seria proveitoso relembrar alguns aspectos do marcante estudo de Hannah Arendt a respeito da dinâmica entre as esferas pública e privada.

\section{ENTRE O PÚBLICO E O PRIVADO}

Em sua obra, A Condição Humana, Hannah Arendt, afirma que a divisão moderna entre público e privado revela, na verdade, uma confusão entre os dois planos, resultado da tendência do desaparecimento da esfera pública e da projeção da esfera privada ao plano do social. Explicando melhor esta idéia, é preciso ter claro que o parâmetro utilizado pela autora para sustentar sua conclusão parte da experiência política grega (exatamente os "antigos" dos quais Benjamin Constant tratava).

Entre os gregos, o privado remetia à atividade humana do labor, ou seja, àquela que se volta para os processos cíclicos de sobrevivência: alimentação, moradia, reprodução. É o espaço da economia por excelência. Enquanto voltado para estas atividades, o homem é visto como um escravo das suas próprias necessidades biológicas, daí porque, para ser verdadeiramente livre, o cidadão grego necessitava de escravos que se encarregassem das atividades econômicas no seu lugar. No privado, todos são iguais na dependência de renovação dos processos cíclicos de sobrevivência, não havendo, inclusive, grandes diferenças em relação aos outros animais.

É no plano público, da polis, que o homem grego poderá afirmar sua singularidade e capacidade de realizar feitos que permanecerão mesmo após a sua morte (o exercício da cidadania substitui aqui a ética do guerreiro relatada na llíada de Homero²). A liberdade só pode existir na esfera pública, onde os homens não são mais escravos das suas necessidades, conseguindo romper a lógica cíclica e indiferenciada da natureza e demarcando uma verticalidade, ou seja, o fato de serem únicos, irrepetíveis e imortais através dos seus feitos na esfera pública, onde

\footnotetext{
${ }^{2}$ No grande poema épico de Homero, a ética do guerreiro é personificada na figura do herói Aquiles, filho da deusa Tétis e do Rei Peleu, que, mesmo tendo sido avisado por sua mãe de que morreria caso participasse da guerra de Tróia, não deixou de integrar a portentosa armada dos reinos gregos, para que assim, em virtude da sua coragem e destreza insuperáveis na batalha, seu nome pudesse ser lembrado e admirado pelos tempos vindouros, atingindo o patamar da imortalidade.
} 
tudo é iluminado, visto e ouvido por todos e onde cada qual, a partir de um ponto de vista singular, olha para algo comum ${ }^{3}$.

A esta atividade humana, diferente do labor e do trabalho, Arendt deu o nome de ação: única atividade que é exercida diretamente entre os homens, sem a mediação das coisas ou da matéria. É a condição humana da pluralidade e de toda vida política. A ação só tem sentido enquanto atividade humana pelo fato de os homens serem, apesar de suas semelhanças, diferentes entre si. Este é o sentido da pluralidade.

$\mathrm{Na}$ medida em que os interesses humanos, no capitalismo moderno, passaram a se voltar muito mais para a riqueza e para a economia, bem como, o individualismo foi se firmando, o plano público passou a enfatizar uma preocupação privada, criando a idéia do social. O Estado nação é como se fosse uma grande família, a igualdade entre os membros da sociedade não é a igualdade entre os pares da polis grega, mas uma igualdade mais próxima aos membros de uma família sujeita à autoridade despótica do seu chefe (responsável pela administração). O chefe de família é substituído pelo monarca, e, depois pela burocracia. As ações são padronizadas e a diferença é expelida para o plano privado.

\section{AS POLÍTICAS DO RECONHECIMENTO}

É claro que toda a nostalgia da polis grega que transpira da análise arenditiana não pode significar simplesmente a bandeira de um retorno a uma democracia excludente. Os cidadãos gregos só podiam dedicar-se integralmente à ação do público às custas da permanência de uma violência constante no privado, que implicava a escravização e a exclusão. Por outro lado, surge com a sociedade moderna o ideal de uma democracia universal e de uma política de reconhecimento de igual dignidade para todos os homens. Em princípio, o público se coloca como um espaço acolhedor para todas as pessoas que compõem a sociedade. Este acolhimento, todavia, tende a eliminar as diferenças, projetando estas para o ambiente privado ou para a intimidade de cada indivíduo. O que se destaca é a

\footnotetext{
${ }^{3}$ A metáfora da mesa, utilizada por Arendt, retrata o "comum" como aquilo que, ao mesmo tempo une e separa as pessoas que estão em sua volta. Esta "mesa" estabelece uma relação entre os que à ela se sentam, revelando-se uma mediação entre as pessoas a respeito de uma mesma questão, de cuja visão cada ocupante de um lugar terá um ângulo diferente (ARENDT, Hannah. A condição humana. 10.ed. Rio de Janeiro: Forense Universitária, 2001. p.62).
} 
igualdade de uma vontade geral ${ }^{4}$, que, historicamente, desde Rousseau, revelou-se pouco tolerante com as vontades dissonantes dentro da mesma sociedade.

De todo modo, à ênfase de Rousseau na participação direta dos indivíduos na esfera pública, sucederá uma sociedade de proprietários que não demanda sua participação no governo, mas sim a ação deste na proteção de sua riqueza (aliás, este já era o próprio sentido do Estado moderno para John Locke no final do século XVII: proteger a propriedade). Com a emergência do Estado social no século XX, continuará a existir uma demanda de ação do governo ao invés de uma demanda na sua participação. Esta tendência levará o Estado social a assumir um viés totalitário e burocratizante 5 .

É claro que, neste meio tempo, é preciso reconhecer que houve uma importante modificação na política de reconhecimento da dignidade igualitária. Ela deixou de se direcionar apenas ao início, ou seja, pressupondo a igualdade entre os indivíduos, e passou a se projetar como conseqüência de um trabalho social na construção de condições para que esta igualdade pudesse ser efetivamente afirmada.

No plano jurídico, este direcionamento implicou na afirmação dos direitos sociais e na crítica aos modelos e conceitos que se voltavam apenas para os direitos individuais $^{6}$. A luta pelos direitos sociais, contudo, não representou apenas a reivindicação perante o governo da satisfação de certas necessidades básicas, ela já deixou as marcas de uma nova idéia de participação da sociedade no plano

4 Desenvolvendo as características desta noção de igualdade, Charles Taylor observa que, em contraposição à sociedade hierárquica anterior, na qual a honra (e a conseqüente diferenciação entre os que a detinham e os que não a detinham) ocupava papel central, a sociedade moderna apoiou-se na noção de dignidade (que se refere a uma potencialidade que todos possuem, mesmo os que não a podem exercer), altamente vinculada à noção de igualdade entre todos os homens. A relação com os outros deve, assim, partir de uma ausência de dominação (liberdade), de uma ausência de papéis diferenciados (igualdade), e da existência de um objetivo comum coeso (fraternidade), para que, assim, seguir a opinião dos outros seja, em verdade, seguir a sua própria. Tal é a fórmula rousseauniana do soberano e do súdito em uma mesma pessoa. O grande problema deste esquema, na opinião de Taylor, é que esta igualdade de estima se apóia em uma unidade de objetivos que parece refratária a qualquer diferenciação, tendo sido "a fórmula usada para os mais terríveis gêneros de tirania homogeneizante, que teve início com os Jacobinos e se prolongou até os regimes totalitários do nosso século." (TAYLOR, Charles. "A política de reconhecimento". In: TAYLOR, Charles. APPIAH, K. Anthony. et. all. Multiculturalismo. Lisboa: Piaget, 1998. p.71).

${ }^{5}$ Uma importante análise a respeito da revolta da subjetividade pessoal e comunitária contra o Estado do Bem-Estar Social encontra-se em: SANTOS, Boaventura de Sousa. Pela mão de Alice - o social e o político na pós-modernidade. 3ª̣ed. Porto: Afrontamento, 1994. p. 203-241.

${ }^{6}$ Um panorama sobre a emergência e os fundamentos do direito social, contrapondo-se à afirmação isolada dos direitos individuais encontra-se em: SILVA FILHO, José Carlos Moreira da. "O direito social e suas significações: o princípio da alteridade.” In: Sánchez Rubio, David; Herrera Flores, Joaquín; Carvalho, Salo de (Orgs). Anuário ibero-americano de direitos humanos (2001/2002). Rio de Janeiro: Lúmen Júris, 2002 , p. 365-399. 
público. A afirmação das demandas sociais, por mais direcionadas ao Estado que fossem, já implicava uma exposição sob os holofotes do público e a afirmação de uma identidade. Esta identidade não era mais a do sujeito autônomo a priori, desenvolvido pela ética kantiana. No início, firma-se a consciência de classe do proletariado, contraposta à classe burguesa, depois, especialmente na segunda metade do século $\mathrm{XX}$, começam a surgir os assim denominados novos movimentos sociais ${ }^{7}$.

Os novos movimentos sociais, surgidos durante a década de 60 (na América Latina a partir da interrupção dos canais tradicionais de participação pela ditadura, e nos países de capitalismo desenvolvido do Ocidente, em função da crise do Welfare State e dos movimentos culturais contestadores, como o dos estudantes), demarcam a afirmação de uma identidade no espaço público que não mais se dá nos espaços tradicionais (partidos políticos, sindicatos, Estado), mas sim no espaço do cotidiano: no bairro, na rua, no campo. Os sujeitos participantes desses movimentos não mais são vistos apenas como sujeitos participantes do processo produtivo, ou integrantes da classe social, mas sim como sujeitos que se definem por uma identidade que não guarda relação direta e necessária com este papel produtivo (mulheres, ambientalistas, negros, índios, moradores, aposentados). A afirmação desta identidade refletiu-se, inclusive, na própria forma de organização e atuação, muito diferente da estrutura hierárquica e institucional dos partidos e dos sindicatos, pois estimulava relações comunitárias e horizontais entre os que participavam nesses movimentos ${ }^{9}$.

Apesar de todas essas diferenças, que colaboram para um novo enfoque do princípio da igualdade, como se verá a seguir, é preciso ponderar que, especialmente na América Latina, e isto mais nas décadas finais do século passado

${ }^{7}$ A despeito de toda a discussão que hoje se desenvolve sobre as possibilidades analíticas deste termo (ver por exemplo: TOURAINE, Alain. Poderemos viver juntos? Iguais e diferentes. Petrópolis: Vozes, 2003), considera-se, aqui, a sua importância no sentido da distinção da política tradicional e de uma transformação, situada no marco da mudança do século, relativa à sua configuração e atividade, como se comentará adiante.

${ }^{8}$ Este caráter de reconfiguração do cotidiano é exemplarmente apontado em alguns estudos clássicos como: SCHERER-WARREN, Ilse, KRISCHKE, Paulo (orgs). Uma revolução no cotidiano? Os novos movimentos sociais na América Latina. São Paulo: Brasiliense, 1987; e SADER, Eder. Quando novos personagens entraram em cena. 2.ed. Rio de Janeiro: Paz e Terra, 1991.

${ }^{9}$ Um quadro analítico quanto ao surgimento histórico destes movimentos, bem como suas demandas, formas de organização e perspectivas até a década de 90 encontra-se no segundo capítulo do livro: SILVA FILHO, José Carlos Moreira da. Filosofia jurídica da alteridade: por uma aproximação entre o pluralismo jurídico e a filosofia da libertação latino-americana. Curitiba: Juruá, 1998. p.128-175. 
do que agora, os novos movimentos sociais articulam-se em torno de demandas semelhantes à reivindicação de direitos sociais da classe trabalhadora, objetivando a satisfação de necessidades fundamentais (emprego, moradia, saúde, condições de trabalho), e endereçam boa parte de suas atividades ao Estado, esperando providências por parte das autoridades públicas. Este padrão ainda se aloja na idéia de que as diferenças sociais são um mal que deve ser eliminado. Em outras palavras, o fato de que os homens não sejam iguais, embora deva ser reconhecido no nível concreto da sociedade, superando um certo liberalismo primitivo, é encarado como algo a ser superado. As políticas públicas do Estado Social e as demandas dos partidos políticos se voltam para este combate. Predomina, assim, uma visão negativa da diferença.

O que os novos movimentos sociais trazem de "novo", especialmente, nos tempos presentes, é uma afirmação positiva da diferença (na Europa Ocidental: imigrantes africanos, indianos, turcos, latinos; na América Latina: povos indígenas, movimento negro). Este é o marco do multiculturalismo, que trás à tona uma outra política de reconhecimento, onde a diferença e a especificidade assumem um espaço de afirmação, indo além do reconhecimento da igual dignidade ${ }^{10}$.

O filósofo canadense Charles Taylor observa, com acuidade, que o tema traz à baila a relação entre identidade e reconhecimento. Antes da era moderna, tal questão não trazia maiores problemas, pois as identidades faziam parte de uma estrutura hierárquica, posta como uma realidade externa, na qual o reconhecimento ocorria naturalmente. A partir daí, contudo, a referência externa da verdade (cósmica ou divina) foi se transferindo ao indivíduo, em um crescente processo de interiorização (fenômeno típico da modernidade, demarcado claramente a partir de Descartes) ${ }^{11}$, e passou a despontar a idéia de que a medida interior, existente em

\footnotetext{
${ }^{10}$ LUIZ EDSON FACHIN descreve, abrangendo do século XVIII até o momento atual, quatro momentos para a noção de igualdade: o primeiro revela a dignidade jurídica do princípio e a sua consideração dentro do sistema, o segundo, a partir do reconhecimento já efetivado, contenta-se com a projeção de uma igualdade meramente formal e abstrata, o terceiro, que ainda se revela como algo a ser conquistado, especialmente em países que, como o Brasil, abriga uma intensa desigualdade social, vê na igualdade um objetivo a ser alcançado mediante um tratamento desigual para os que são desiguais, especialmente aos que, em virtude desta dessa desigualdade são atingidos concretamente em sua dignidade. O quarto momento seria o do reconhecimento das desigualdades. Afirma FACHIN: "O fator decisivo deixa de ser apenas a busca de uma igualdade a todo e qualquer custo, mas o de reconhecer que certas diferenças, em si mesmas, não são necessariamente discriminatórias." (FACHIN, Luiz Edson. Teoria crítica do direito civil. Rio de Janeiro: Renovar, 2000. p.286).

11 TAYLOR, Charles. As fontes do self: a construção da identidade moderna. São Paulo: Loyola, 1997. p.149-270.
} 
cada indivíduo de modo único, próprio e original, é que deve lhe servir de guia na vida em sociedade (autonomia moral). A identidade é assim "individualizada".

O reconhecimento passou a ser um problema, algo que precisa ser negociado com os outros membros da sociedade, já que agora a medida da identidade é o próprio indivíduo. O não reconhecimento ou o reconhecimento incorreto revela-se uma ofensa e uma ameaça à própria sobrevivência da identidade que se busca afirmar, já que induz a uma autodepreciação ${ }^{12}$.

Essa necessidade de reconhecimento se expressa em duas políticas de reconhecimento distintas (já comentadas anteriormente): a da igual dignidade e a da diferença. Esta última, por sua vez, encontrará suas bases no que, segundo Taylor, é uma das mais importantes (e incompreendidas) fontes morais da era moderna: a autenticidade.

\section{INDIVIDUALIZAÇÃO E AUTENTICIDADE}

A emergência do ideal da autenticidade, porém, se dá em um contexto de crescente individualização, que tem sido acompanhado com grande preocupação por alguns estudiosos da contemporaneidade. Bauman, por exemplo, concorda em que, hoje, as identidades estão cada vez mais a cargo dos indivíduos do que das instituições. A marca registrada da sociedade moderna é a apresentação de seus membros como indivíduos. Todavia, o significado da "individualização" muda continuamente, trazendo sempre uma tarefa a ser cumprida. É preciso tornar-se o que já se é. A afirmação da identidade é uma imposição, já que não há mais a determinação heterônoma da posição social.

Neste ponto, Bauman vai um pouco mais longe e afirma que as classes sociais (e não apenas os postos da sociedade hierárquica pré-moderna) eram percebidas como dados da natureza onde as pessoas se acomodariam para sua autoafirmação, já que sozinhas dificilmente poderiam fazê-lo (era necessário algum

\footnotetext{
12 Tratando-se especificamente da América Latina, a luta pelo reconhecimento cultural se dá no marco da necessária superação de um certo "mito da inferioridade latino-americana". Em outro artigo, teve-se a oportunidade de desenvolver o sentido desta autoimagem depreciativa, que se torna visível no que Dussel apontou como "os vários rostos latino-americanos" (índios, negros, mestiços, crioulos). Ver: SILVA FILHO, José Carlos Moreira da. "Da 'invasão'da América aos sistemas penais de hoje: o discurso da 'inferioridade'latinoamericana". In: WOLKMER, Antonio Carlos (org.). Fundamentos de história do direito. 2.ed. Belo Horizonte: Del Rey, 2001. p.279-329; DUSSEL, Enrique. 1492 - o encobrimento do outro (a origem do mito da modernidade). Petrópolis: Vozes, 1993.
} 
acolhimento institucional). Hoje, no que o sociólogo polonês chama de "modernidade líquida", estes confortáveis lugares para reacomodação são efêmeros e fugidios. Agora a individualização é uma fatalidade, não uma escolha. Se há alguma institucionalização estável ela é a do individualismo ${ }^{13}$.

Hoje, os problemas e as questões individuais são postas de maneira não aditivas, dificultando o "cerrar fileiras" em torno de grandes questões comuns. A única vantagem na presença dos outros residiria na percepção de que eles também têm de enfrentar seus próprios problemas, o que reforçaria uma atitude responsável e individualizada. O que se pode aprender com os outros é talvez como sobreviver solitariamente e como encarar os contínuos riscos (daí o crescimento do mercado de auto-ajuda). O indivíduo livre, ao contrário do cidadão, tende a ser indiferente diante da busca do bem-comum. O único sentido pertinente do bem-comum é permitir que cada indivíduo possa cuidar de seus próprios interesses ${ }^{14}$.

O outro lado da individualização, conclui Bauman, é a lenta e progressiva corrosão da cidadania. O público é colonizado pelo privado. O interesse público passa a ser a curiosidade sobre as vidas privadas de pessoas públicas e a exposição pública de questões privadas. O método que restou de construção da comunidade foi o compartilhar de experiências íntimas. Tal processo leva à formação de comunidades frágeis e fugidias. Há um isolamento e uma confinação do ego.

Procurando contemporizar as análises fatalistas deste processo de individualização ${ }^{15}$, Taylor vê nas tendências visíveis e concretas de um relativismo individualista que não se preocupa com os temas comunitários apenas uma das possibilidades oriundas da fonte mais ampla de um individualismo que busca sua

13 Sobre o individualismo institucionalizado ver: BECK, Ulrich, BECK-GERNSHEIM, Elisabeth. La individualización - el individualismo institucionalizado y sus consecuencias sociales y políticas. Barcelona: Paidós, 2003.

14 Neste cenário, o Estado se transforma praticamente em uma delegacia de polícia. "As únicas duas coisas úteis que se espera e se deseja do 'poder público' são que ele observe os 'direitos humanos', isto é, que permita que cada um siga seu próprio caminho, e que permita que todos o façam 'em paz - protegendo a segurança de seus corpos e posses, trancando criminosos reais ou potenciais nas prisões e mantendo as ruas livres de assaltantes, pervertidos, pedintes e todo tipo de estranhos constrangedores e maus." (BAUMAN, Zygmunt. Modernidade líquida. Rio de Janeiro: Jorge Zahar, 2001. p.45).

15 Importante assinalar que Bauman certamente não chega a ser um autor que condena o processo de individualização de modo absoluto ou que não veja nele uma possibilidade de evitar o desprezo pelas questões comuns, mas, de todo modo, a argumentação que desenvolve nesta parte do seu estudo ajuda a ilustrar um discurso que pode ser encontrado, conforme indica Taylor, em autores como Daniel Bell e Christopher Lasch, para os quais predomina um tom apocalíptico. 
auto-satisfação (e uma possibilidade desviada, deve-se frizar). Para o filósofo canadense, na verdade, a idéia de que os indivíduos não se importam com nada a não ser consigo próprios é um desvio do ideal da autenticidade.

O pensamento desenvolvido no século XX a partir da linguistic turn mostrou que a constituição da razão humana é dialógica. A identidade individual não se dá no vazio ou a partir de si mesma, ela se forma a partir de uma compreensão existencial que Ihe é legada pela tradição histórica e que se dá na linguagem ${ }^{16}$. Há, pois, um horizonte onde as coisas fazem sentido e a partir do qual as escolhas são feitas. A afirmação da diferença não deve ser encarada, portanto, como uma negação de qualquer horizonte comum. Taylor critica aqui uma certa retórica da diferença (assumida por vezes pelo multiculturalismo) ${ }^{17}$ que focaliza a escolha e menospreza o horizonte prévio sobre o qual se fez esta escolha. Se não existir um horizonte significativo prévio, a escolha deixa de ter importância, pois tanto faz o seu conteúdo.

O reconhecimento da diferença pressupõe, pois, um espaço de efetivo diálogo sobre a coisa da qual se trata (como diria Gadamer). No debate entre universalismo e relativismo, que grassa na temática do multiculturalismo, por exemplo, é preciso que, com vistas a superar este impasse e promover uma efetiva política de reconhecimento das diferenças, cada cultura possa, a partir dos seus preconceitos ou horizontes, bem como do reconhecimento de que neles se apóiam (e não que o seu enfoque é respaldado pela ordem natural das coisas), promover com as outras culturas uma fusão de horizontes $^{18}$, na qual, cada uma das partes assuma o risco de alterar a sua compreensão quanto aos temas discutidos. A tradição só pode sustentar a compreensão e o debate se dela os sujeitos se

16 Neste ponto não se pode deixar de fazer referência à importância do pensamento de Martin Heidegger, com sua ontologia fundamental, e de Hans-Georg Gadamer com sua hermenêutica filosófica. Para maiores informações a respeito do pensamento destes indispensáveis filósofos, ver: SILVA FILHO, José Carlos Moreira da. Hermenêutica filosófica e direito: o exemplo privilegiado da boa-fé objetiva no direito contratual. 2.ed. Rio de Janeiro: Lúmen Júris, 2005.

17 TAYLOR, Charles. The ethics of authenticity. Cambridge: Harvard University, 2000. p.37.

18 Taylor acena explicitamente com o uso desta importante categoria gadameriana para propor que, a partir do pressuposto de igual valor entre culturas tradicionais, não se deve, automaticamente, assumi-lo como uma conclusão definitiva, isto é, o verdadeiro juízo de valor pressupõe um horizonte fundido de critérios. Sem este, o juízo de valor é etnocêntrico e condescendente, estando longe de um respeito genuíno e desprezando-se a inteligência de quem é "reconhecido", diminuindo-o em sua condição de sujeito (TAYLOR, Charles. "A política de reconhecimento". In: TAYLOR, Charles. APPIAH, K. Anthony. et. all. Multiculturalismo. Lisboa: Piaget, 1998. p.91). 
apropriarem $^{19}$. Há uma grande diferença entre saber que existe uma tradição cultural distinta e procurar compreendê-la. Neste último caso, é preciso supor que o outro tenha algo importante a dizer e, verdadeiramente, postar-se à escuta, para que daí possa, de fato, surgir um diálogo e um possível consenso.

\section{CONSIDERAÇÕES FINAIS}

Em tempos de individualização, de desmantelamento do público tradicional, de afirmação de identidades autênticas e de risco de uma anomia comunitária, os espaços criados pelos novos movimentos sociais e suas redes ${ }^{20}$ revelam-se, por mais frágeis e instáveis que sejam, uma possibilidade importante na busca de uma reconstrução da esfera pública ${ }^{21}$. Ao tornarem questões privadas, públicas (não apenas aquelas às quais Bauman se referia, mas também as questões de gênero, étnicas, sexuais e outras) e ao associarem tais temas com a tradicional luta pelos direitos sociais, tais movimentos contribuem para tornar transparente a toda sociedade estas questões, construindo um novo espaço comum, onde não há nada assegurado em termos institucionais, onde a solidez da "modernidade pesada" abre terreno para um processo contínuo de diálogo e busca de consensos, consciente dos riscos de uma individualização descomprometida e de uma indiferenciação no espaço comum promovida pelo que restar no vácuo da ausência de um efetivo esforço comunitário: a padronização monetária de tudo e todos, a exclusão e a violência.

Ao voltar as costas para a necessária discussão e participação no público, reconhecendo os novos termos em que isto pode se dar, a tão acalentada liberdade dos modernos, defendida por Benjamin Constant, de castelo inexpugnável se

\footnotetext{
${ }^{19}$ A apropriação da tradição é um dos temas mais ricos e importantes que Gadamer desenvolve em sua obra básica. Ver: GADAMER, Hans-Georg. Verdade e método - traços fundamentais de uma hermenêutica filosófica. Petrópolis: Vozes, 1997.

20 Uma análise pioneira dos movimentos sociais a partir das redes encontra-se em: SCHERERWARREN, Ilse. Redes de movimentos sociais. 2.ed. São Paulo: Loyola, 1996.

${ }^{21}$ Corroborando o esforço de análises como a de Taylor, Pietro Barcellona afirma que "la alternativa no se da entre individualismo y comunidad, sino entre los vínculos que se establecen em uma comunidad no querida y fundamentada em el domínio del jefe y el reconocimiento consciente de la sociabilidad estructural del individuo concreto. La comunicación com el outro, como base necesaria para la confirmación de mi identidad, puede abrir la puerta a uma forma distinta del estar juntos." (BARCELLONA, Pietro. Postmodernidad y comunidad. 2.ed. Madri: Editorial Trotta, 1996. p.114).
} 
transforma em frágil e escapadiça tábua de salvação em meio ao mar revolto da precarização das relações sociais.

\section{REFERÊNCIAS BIBLIOGRÁFICAS}

ARENDT, Hannah. A condição humana. 10.ed. Rio de Janeiro: Forense Universitária, 2001.

BARCELLONA, Pietro. Postmodernidad y comunidad. 2.ed. Madri: Editorial Trotta, 1996.

BAUMAN, Zygmunt. Modernidade líquida. Rio de Janeiro: Jorge Zahar, 2001.

BECK, Ulrich, BECK-GERNSHEIM, Elisabeth. La individualización - el individualismo institucionalizado y sus consecuencias sociales y políticas. Barcelona: Paidós, 2003.

CONSTANT, Benjamin. "Da liberdade dos antigos comparada à dos modernos." In: Filosofia política, Porto Alegre, L\&PM, 1985. p. 9-25.

DUSSEL, Enrique. 1492 - o encobrimento do outro (a origem do mito da modernidade). Petrópolis: Vozes, 1993.

FACHIN, Luiz Edson. Teoria crítica do direito civil. Rio de Janeiro: Renovar, 2000.

GADAMER, Hans-Georg. Verdade e método - traços fundamentais de uma hermenêutica filosófica. Petrópolis: Vozes, 1997.

HEIDEGGER, Martin. El ser y el tiempo. 2.ed. México: Fondo de Cultura Económica, 1997.

SANTOS, Boaventura de Sousa. Pela mão de Alice - o social e o político na pós-modernidade. 3ª̣ed. Porto: Afrontamento, 1994.

SCHERER-WARREN, Ilse. Redes de movimentos sociais. 2.ed. São Paulo: Loyola, 1996.

SCHERER-WARREN, Ilse, KRISCHKE, Paulo (orgs). Uma revolução no cotidiano? Os novos movimentos sociais na América Latina. São Paulo: Brasiliense, 1987.

SADER, Eder. Quando novos personagens entraram em cena. 2.ed. Rio de Janeiro: Paz e Terra, 1991.

SILVA FILHO, José Carlos Moreira da. Hermenêutica filosófica e direito: o exemplo privilegiado da boa-fé objetiva no direito contratual. 2.ed. Rio de Janeiro: Lúmen Júris, 2005.

"O direito social e suas significações: o princípio da alteridade." In: Sánchez Rubio,

David; Herrera Flores, Joaquín; Carvalho, Salo de (Orgs). Anuário ibero-americano de direitos humanos (2001/2002). Rio de Janeiro: Lúmen Júris, 2002, p. 365-399. 
. "Da 'invasão'da América aos sistemas penais de hoje: o discurso da 'inferioridade'latino-americana". In: WOLKMER, Antonio Carlos (org.). Fundamentos de história do direito. 2.ed. Belo Horizonte: Del Rey, 2001. p.279-329.

Filosofia jurídica da alteridade: por uma aproximação entre o pluralismo jurídico e a filosofia da libertação latino-americana. Curitiba: Juruá, 1998.

- "Transformações jurídicas nas relações privadas". In: ROCHA, Leonel Severo; STRECK, Lênio Luiz (orgs.). Anuário do Programa de PósGraduação em Direito - 2003. São Leopoldo: UNISINOS, 2004. p.143-195.

TAYLOR, Charles. The ethics of authenticity. Cambridge: Harvard University, 2000.

TAYLOR, Charles. "A política de reconhecimento". In: TAYLOR, Charles et.al. Multiculturalismo. Lisboa: Piaget, 1998. p.45-94.

TAYLOR, Charles. As fontes do self: a construção da identidade moderna. São Paulo: Loyola, 1997. TOURAINE, Alain. Poderemos viver juntos? Iguais e diferentes. Petrópolis: Vozes, 2003. 